\title{
Need for involving consumers in Nepal's pharmacovigilance system
}

\author{
Nisha Jha ${ }^{1}$, Devendra Singh Rathore², P Ravi Shankar ${ }^{3}$, Bhupendra Bahadur Thapa ${ }^{4}$, \\ Gajendra Bhuju ${ }^{5}$, Mohammed Alshakka ${ }^{6}$
}

1. KIST Medical College, Nepal 2. L.R. Institute of Pharmacy, Himachal Pradesh, India, 3. Xavier University School of

Medicine, Aruba, 4. Former Chief Drug Administrator, Ministry of Health and Population, Nepal, 5. Director General,

Department of Drug Administration, Nepal, 6. Faculty of Pharmacy, Aden University, Yemen

\section{BRIEF REPORT}

Please cite this paper as: Jha N, Rathore DS, Shankar PR, Thapa BB, Bhuju G, Alshakka M. Need for involving consumers in Nepal's pharmacovigilance system. AMJ 2014, 7, 4, 191-195. http://doi.org/10.21767/AMJ.2014.2011

Corresponding Author:

Ms. Nisha Jha

Lecturer

Department of Clinical Pharmacology and Therapeutics, KIST Medical College, Nepal and PhD Research Scholar, Suresh Gyan Vihar University, Jaipur, India

Email: nishajha32@gmail.com

\section{ABSTRACT}

In Nepal, reporting of adverse drug reactions (ADRs) occurs on a voluntary basis by doctors, pharmacists, nurses, health assistants, and other healthcare professionals. The country's pharmacovigilance program is still in its infancy; it has limited coverage and underreporting is common. This major limitation could be reduced with consumer involvement. This report examines the necessity and benefits of consumer involvement in Nepal's existing pharmacovigilance program, reflecting on existing examples of consumer pharmacovigilance in different countries to highlight the necessity for such a framework in Nepal.

\section{Key Words}

Consumers, Nepal, pharmacovigilance

\section{What this study adds:}

\section{What is known about this subject?}

Consumer involvement in pharmacovigilance is accepted in many countries and has been started in some developing countries such as Malaysia.

2. What new information is offered in this study? This report highlights possible reasons for underreporting of adverse drug reactions. It presents strategies for initiating consumer pharmacovigilance in Nepal based on experiences from other developing countries.

3. What are the implications for research, policy, or practice?

Involving consumers can strengthen Nepal's national pharmacovigilance program by helping to overcome the problem of underreporting, which is a drawback of the voluntary reporting systems used in various countries.

\section{Background}

Adverse drug reactions (ADRs) are a major cause for morbidity and mortality worldwide. ${ }^{1,2}$ The World Health Organization (WHO) defines an ADR as "a response to a drug which is harmful and unintended, and which occurs at doses normally used in man for the prophylaxis, diagnosis, or therapy of disease or for the modification of body functions". ${ }^{3}$ Nepal's Department of Drug Administration (DDA) within the Ministry of Health and Population was established as per the Drug Act of 1978. The DDA regulates the manufacture, import/export, sales, distribution, and storage of drugs in Nepal. ${ }^{4}$ The DDA is also home to the National Centre for Pharmacovigilance, which was established in 2004. Nepal became a member of the International Pharmacovigilance Program in 2007. ${ }^{5,6}$

Nepal's existing system for monitoring ADRs relies on voluntary reporting by health professionals as its main source of information. There is no provision for reporting by consumers and the general public. This article describes the need for, and the benefits of, involving consumers in Nepal's existing pharmacovigilance program. It also explores the current status of consumer pharmacovigilance in different countries, highlighting the urgent need for initiating the same framework in Nepal.

\section{Consumer pharmacovigilance in other countries}

The United States of America was the first country to initiate ADR reporting by consumers. From 1960, 
Figure 1: The Pharmacovigilance Framework ${ }^{15}$

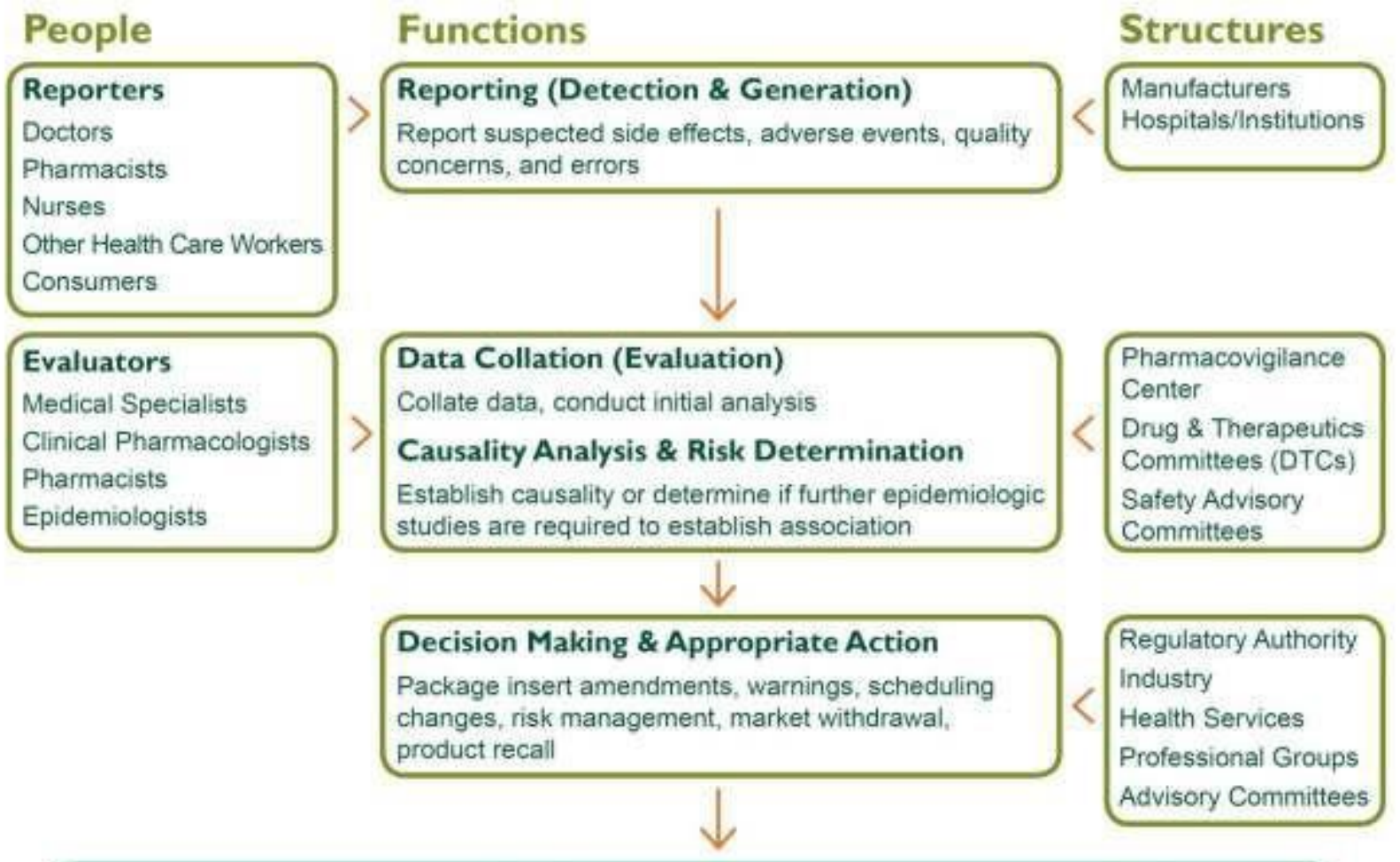

Prevented medicine-related problems $\mid$ Reduced morbidity and mortality

consumers could report directly to the Food and Drug Administration (FDA). ${ }^{7}$ Similarly, in 2003 consumers in the Netherlands started reporting ADRs to Lareb, a foundation established separate to the country's national drug regulatory authority. Denmark followed suit soon after, followed by Italy in 2004, the UK and Sweden in 2008, and Norway in 2013. ${ }^{8-10}$ Consumers can report directly to the medicine agencies or indirectly through consumer organisations, and can also submit reports electronically, on paper, or by telephone.

The Netherlands' experience, detailed for a three-year period, showed that patient reporting is a good source of information for monitoring of drug safety. The UK's Medicines and Healthcare Products Regulatory Agency (MHRA) team concurred and showed further evidence and advantage from the international experience regarding patient reporting of ADRs. ${ }^{11}$ Authors from Sri Lanka have suggested that consumer reporting is the best method for developing countries to overcome underreporting and could complement the existing system of reporting by physicians and pharmacists. ${ }^{12}$

Nepal's pharmacovigilance system is still in its infancy. There is no provision for consumers to report ADRs in the existing structure; however, a new initiative for consumers is strongly warranted along with encouragement for healthcare professionals and other stakeholders to promote pharmacovigilance and consumer pharmacovigilance in Nepal.

\section{Policy, law and regulation}

Nepal's Drug Act of 1978 and National Drug Policy (NDP) of 1995 address elements of medicine safety and public health.

Pharmacovigilance and consumer pharmacovigilance is not yet addressed in the policy documents of many of Nepal's health institutions, industry, medical professional organisations, or public health programs. Realising the need to address pharmacovigilance within the country's national policies, laws, and regulations, Nepal's national medicine policy is under review. This review includes several important elements related to implementing the national pharmacovigilance program and the conduct of pharmacovigilance among variousstakeholders. ${ }^{13}$

\section{Systems, structures, and coordination among stakeholders}

Nepal has had a mechanism for reporting suspected adverse drug reactions since 2006 . Its national pharmacovigilance program includes both the national centre within the DDA and seven regional pharmacovigilance centres located within health facilities throughout Nepal, many of which routinely report suspected ADRs to the national pharmacovigilance centre through an established database. Regional centres collect 
ADR reports from healthcare professionals and send them to the DDA. From there, reports are sent to the Uppsala Monitoring Centre in Sweden, a centre for international service and scientific research towards patient safety. ${ }^{14}$

Regional centres in Nepal are currently functioning with inadequate human and financial resources. Figure 1 shows the people, functions, and structures that are required for an effective pharmacovigilance framework. Consumers are not yet included in Nepal's pharmacovigilance program.

\section{Signal generation}

The DDA has designed a national ADR reporting form available on its website. Different regional centres have their own data collecting ADR forms, but many people inside and outside the regional pharmacovigilance centres are not yet aware of the form's existence and its intended use as a reporting mechanism for suspected ADRs.

The WHO indicates that fully functional pharmacovigilance systems should expect to receive 200 ADR reports per million population; for Nepal, that's 6,097 ADR reports per year for its population of 30.5 million. ${ }^{16}$ Due to many limiting factorse.g., lack of full-time dedicated staff responsible for pharmacovigilance activities, public awareness programs, and standard guidelines for pharmacovigilance-only 523 reports have been received since 2006 .

Strategies to increase both voluntary and mandatory ADR reporting from various stakeholders are needed. The authors recommend the following:

- Simplify the national ADR form so that consumers can use it.

- Design a separate form that is available in the Nepali language and other local languages.

- Make this consumer reporting form available at every regional centre and also on the DDA's website.

Consumer access to the form should be easy, as should the reporting process. Reporting can be done voluntarily via telephone, email, and text messaging. Advantages of consumer reporting include details on new types of reactions, an increase in the number of ADRs being reported, early detection of ADRs and developing a strategy for the same, prevention of medication errors, detailed information on patient's quality of life, and obtaining reports from elderly people, and pregnant women. ${ }^{17,18}$

\section{Need and benefits of consumer reporting}

As shown in Figure 1, consumers are supposed to be an important group in the pharmacovigilance framework. They can report any ADRs and thereby spare others from similar types of suffering/reactions in the future. Integrating consumers into Nepal's pharmacovigilance program is strongly recommended by the authors because self-medicating is common and medicines are easily available without a prescription. ${ }^{19}$

Nepal currently needs consumer pharmacovigilance because:

1. Greater awareness among consumers will reduce the harmful effects and suffering caused by medicines. ${ }^{17}$

2. The problem of underreporting must be overcome. Doctors are often reluctant to report ADRs for fear of legal liability, or indictment of bad practice. ${ }^{20}$

3. Most doctors and other healthcare professionals in Nepal are unaware of the system for monitoring and reporting ADRs.

4. The Nepali population differs in many respects to other developed countries, with regard to genetics, the medicine manufacturing process, use of traditional medicines, and poor availability of quality healthcare services.

5. Consumer reporting can promote consumer rights and equity. ${ }^{21}$

6. Consumers can provide unique perspectives and experiences. $^{21}$

\section{The role of community pharmacists in} pharmacovigilance

Community pharmacists serve the Nepalese community throughout the country, and play an important role in healthcare delivery. Community pharmacies are run by people with a diploma or bachelor's degree in pharmacy, or who have obtained orientation training in drug dispensing. ${ }^{22}$ People can readily access community pharmacies and are often the first point of contact with the health system. Self-medicating is prevalent in Nepal; people generally prefer to consult community pharmacists about their health problems. ${ }^{19}$ Given these facts, community pharmacists can play an important role in Nepal's pharmacovigilance system by educating patients about the importance of reporting ADRs, and by forwarding $A D R s$ to the regional pharmacovigilance centres. They can be considered as a key health service provider at the community level who can help promote medication safety. 


\section{Challenges for initiating consumer pharmacovigilance in Nepal}

Nepal is a developing country and faces many obstacles for having a good pharmacovigilance program. Major constraints include: low literacy levels, low awareness, poor knowledge about issues related to ADRs, high levels of self-medication, local language problems, communication problems, and lack of dedicated human resources to take responsibility in all the regional centres. Other challenges are lack of funding for campaigns to increase public awareness about ADRs, political instability, and the social and logistical difficulties of both organizing and involving consumer forums and discussion groups regarding the initiation of sustainable pharmacovigilance programmes. Despite these constraints, the authors are hopeful for a systematic and proper initiation for consumer pharmacovigilance in Nepal.

Research conducted among consumers of 11 countries, including Australia, Canada, Denmark, the Netherlands, New Zealand, Norway, Malaysia, the Philippines, Sweden, the UK, and the US revealed the benefits of public reporting of ADRs with regard to the scientific value of the collected data. ${ }^{23}$ Australia and Sweden have effective ADR reporting systems as well as consumer involvement compared to the other countries. Looking at these countries, we can expect improved reporting rates, a different perspective from health professionals, and reduced suffering and safer use of medicines.

Currently in Nepal, suspected ADR data is generated primarily by the seven regional pharmacovigilance centres and only infrequently from national public health programs, industries, and pharmacies. The current ADR reporting system is restricted to physicians, nurses, pharmacists, and other healthcare service providers. As demonstrated in other countries, consumers can strengthen the existing system of pharmacovigilance. There should be an awareness program for people across all levels, including public health programs, health facilities, pharmacies, industry, consumer groups, academia, and associations for healthcare professionals. ${ }^{13} \mathrm{At}$ present, the DDA organises WHO-funded seminars and activities related to pharmacovigilance once every two years. At present, there is a strong need to establish some coordination of ADR reporting activities among all the stakeholders in Nepal to promote consumer pharmacovigilance. ${ }^{13}$

\section{Conclusion}

Consumer-driven pharmacovigilance has been successful in many countries and such a framework is urgently needed in Nepal to address the current levels of ADRs. Pharmacists in Nepal need to be intimately involved in the discussion, planning, and delivery of consumer pharmacovigilance. Promoting this type of reporting will enhance safe medicine use among consumers. Involving consumers has many benefits and could contribute to decreasing the current problem of underreporting of ADRs in Nepal.

\section{References}

1. Davies EC, Green CF, Taylor S, Williamson PR, Mottram DR, Pirmohamed M. Adverse drug reactions in hospital in-patients: a prospective analysis of 3695 patient-episodes. PLoS One. 2009;4:e4439.

2. Davies EC, Green CF, Mottram DR, Pirmohamed M. Adverse drug reactions in hospitals: a narrative review. Curr Drug Saf. 2007;2:79-87.

3. World Health Organization. Requirements for adverse reaction reporting. Geneva, Switzerland: World Health Organization; 1975.

4. Drug act 2035. Department of Drug Administration, Nepal. 1978 Available online at: http://www.dda.gov.np/drugact.php.

5. Nepal joins programme. Uppsala reports 2007;36:5-6 Available at:http://who-umc.org/graphics/24365.pdf

6. Subish P, Mohamed I, Mishra P. Pattern of adverse drug reaction reported by community pharmacist in Nepal. Pharm Pract (Granada) 2010;8:201-7.

7. Herxheimer A, Crombag MR, AlvesC TL. Direct patient reporting of adverse drug reactions. A twelve-country survey and literature review. Briefing Paper Health Action International. January 2010. Available at: http://www.haiweb.org/14012010/14Jan2010Report DirectPatientReportingofADRsFINAL.pdf.

8. Langen J, van Hunsel, Passier, van den Berg L, van Grootheest K Adverse Drug Reactions Reporting by Patients in the Netherlands. Drug Saf. 2008;31:51524.

9. Medawar C, Herxheimer A. A comparison of adverse drug reaction reports from professionals and users, relating to risk of dependence and suicidal behaviour with paroxetine. Int J Risk Saf Med. 2003;16:5-19.

10. Van Grootheest AC, de Jong-van den Berg L. Review: Patients' role in reporting adverse drug reactions. Exp Opin Drug Saf. 2004;3:363-68.

11. Blenkinsopp A,Wilkie $P$,Wang $M$, Routledge PA. Patient reporting of suspected adverse drug reactions: a review of published literature and internationale experience. $\mathrm{Br} J$ Clin Pharmacol. 2006;63:148-56.

12. Fernandopulle RBM, Weerasuriya $K$. What can consumer adverse drug reaction reporting add to 
existing health professional-based systems. Drug Saf. 2003;26:219-25.

13. Shrestha, NP, Ludeman, E. "Safety of Medicinal Products in Nepal: Pharmacovigilance Assessment and Performance." Submitted to the US Agency for International Development by the Systems for Improved Access to Pharmaceuticals and Services (SIAPS) Program, Management Sciences for Health, Arlington, VA, USA. February 2013.

14. Jha N, Shankar PR, Bajracharya O, Gurung SB, Singh KK. Adverse drug reaction reporting in a pharmacovigilance centre of Nepal. Australas Med J. 2012;5:268-71.

15. Strengthening Pharmaceutical Systems (SPS). 2009. Supporting Pharmacovigilance in Developing Countries: The Systems Perspective. Submitted to the U.S. Agency for International Development by the SPS Program. Arlington, VA: Management Sciences for Health.

16. World Bank, 2011. Available online at: http://data.worldbank.org/country/nepal.

17. Potharaju HR. Reporting of Adverse Drug Reactions by Consumers: Rationale and Potential. Pharmbit. 2010;22(2):14-21.

18. Ahmed AM, Ibrahim MIM, Subish P. Importance of consumer pharmacovigilance system in developing countries: a case of Malaysia. J Clin Diagn Res. 2010;4:2929-35.

19. Shankar PR, Partha P, Shenoy N. Self-medication and nondoctor prescription practices in Pokhara valley, Western Nepal: a questionnaire-based study. BMC Fam Pract. 2002;3:17.

20. Olsson S. National pharmacovigilance systems, $2^{\text {nd }}$ edition, Uppsala Monitoring centre, 1999.;789-812.

21. Direct Reporting by Consumers - First International Conference. WHO Pharmaceutical Newsletters [online]. Available from URL: www.fda.gov/medwatch/safety/ar95.pdf

22. Bhuvan KC, Alrasheedy AA, Mohamed Izham MI. Do community pharmacists in Nepal have a role in adverse drug reaction reporting systems? Australas Med J. 2013;6:100-103.

23. Van Hunsel F, Harmark L, Pal S. Experiences with Adverse Drug Reaction Reporting by Patients: An 11-Country Survey. Drug Saf. 2013;35:45-60.

\section{ACKNOWLEDGEMENTS}

The authors acknowledge the staff of the Department of Drug Administration, Nepal for providing information related to pharmacovigilance and consumers pharmacovigilance system in Nepal. The authors also acknowledge pharmacist Mr. Nabin Prasad Shrestha for giving permission to use the figure for the pharmacovigilance framework.

\section{PEER REVIEW}

Not commissioned. Externally peer reviewed.

\section{CONFLICTS OF INTEREST}

The authors declare that they have no competing interests. 